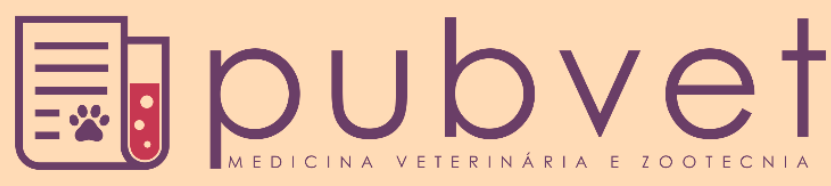

https://doi.org/10.31533/pubvet.v15n07a857.1-4

\title{
Complexo granuloma eosinofilico felino: Relato de caso
}

\author{
Mary'Anne Rodrigues de Souza ${ }^{1 * \bullet}$, Flávia Naianny Alves de Jesus ${ }^{2}{ }^{\bullet}$, Ellen Eduarda Julião \\ Santos $^{2}{ }^{\circ}$, Emilly Roanita Santana Silva ${ }^{2}{ }^{\circ}$, Ingrid Stephani dos Santos Gomes ${ }^{2}{ }^{\circ}$, Francielle \\ Menezes de Oliveira $^{2}{ }^{\circ}$, Taiwane Nelis dos Santos Nascimento ${ }^{2}$, Thais Maria Gois Souza $^{2} \bullet$
}

${ }^{1}$ Professora da Faculdade Pio Décimo, Departamento de Medicina Veterinária. Aracaju-SE, Brasil.

${ }^{2}$ Graduanda em Medicina Veterinária, Faculdade Pio Décimo. Aracaju-SE, Brasil.

*Autor para correspondência, E-mail: mary.souza@piodecimo.edu.br

\begin{abstract}
Resumo. O complexo granuloma eosinofílico felino (CGE), é uma dermatopatia comum em felinos, caracterizada por três tipos de lesões: úlceras indolentes (UI), placas eosinofílicas (PE) e granuloma eosinofílico (GE). As lesões podem se manifestar na pele e cavidade oral dos gatos, podem ser bastante severas e causar níveis diferentes de prurido e de dor. Desse modo, o objetivo desse trabalho é relatar o caso de um felino jovem, com complexo granuloma eosinofilico, que possuía granulomas eosinofilicos na cavidade oral, úlceras indolentes nos coxins palmares e plantares, dispnéia inspiratória e espirros há cerca de um mês. O diagnóstico do CGE foi realizado pelos sinais clínicos e exame citológico dos nódulos orais, sendo a hipersensibilidade a picada de pulgas, considerada a causa primária das lesões. O tratamento foi medicamentoso, com predinisolona e com o parafelis ${ }^{\circledR}$, para controle da infestação de pulgas. Após o tratamento, não houve relato de recidiva.
\end{abstract}

Palavras-chave: Felinos, dermatologia, histopatológico

\section{Feline eosinophilic granuloma complex: Case report}

\begin{abstract}
The feline eosinophilic granuloma complex (EGC) is a common dermatopathy in felines, characterized by three types of lesions: indolent ulcers (UI), eosinophilic plaques $(\mathrm{PE})$, and eosinophilic granuloma (GE). Lesions can manifest on the skin and oral cavity of cats, can be quite severe and cause different levels of itching and pain. Thus, the objective of this work is to report the case of a young feline, with eosinophilic granuloma complex, who had eosinophilic granulomas in the oral cavity, indolent ulcers in the palmar and plantar cushions, inspiratory dyspnea and sneezing for about a month. The diagnosis of EGC was made through clinical signs and cytological examination of oral nodules, being the hypersensitivity to flea bites, considered the primary cause of the lesions. The treatment was medicated, with predinisolona and parafelis ${ }^{\circledR}$, to control flea infestation. After the treatment, there was no report of recurrence.
\end{abstract}

Keywords: Dermatology, felines, histopathological

\section{Introdução}

O complexo granuloma eosinofílico felino (CGE) é uma síndrome que compreende um grupo de dermatoses comuns em gatos, que possui três principais lesões clínicas primárias que são: úlcera indolente (UI), placa eosinofilica (PE) e o granuloma eosinofilico (GE). Estas lesões são secundárias às reações de hipersensibilidade desencadeadas por dermatites alérgicas provocadas por picadas de pulgas e mosquitos, atopia, hipersensibilidade alimentar, predisposição genética, idiopática, entre outros (Buckley \& Nuttall, 2012). O CGE poder ser 
causado por uma variedade de fatores, mas a manifestação cutânea de doença alérgica felina é a mais comumente encontrada (Hopke \& Sargent, 2019).

A patogenia da doença está ligada a um padrão de reatividade cutânea a ação dos mastócitos e eosinófilos, ou seja, está relacionada basicamente, a uma resposta indevida dos eosinófilos a vários estímulos, resultando em uma reação cutânea (Lerner, 2018).

O diagnóstico do CGE é realizado através de uma anamnese detalhada, do histórico do animal, sinais clínicos, exames citológicos e histopatológicos, que confirmam a suspeita (Buckley \& Nuttall, 2012). O histórico do animal é de suma importância, pois contém informações sobre possíveis causas alérgicas, sazonalidade, ou relação com diagnóstico de atopia ou hipersensibilidade à picada de insetos (Rodrigues, 2016). A anamnese deve ser feita de forma detalhada, adquirindo informações acerca do início das lesões, sinais clínicos, presença ou ausência de lambedura ou prurido, estado geral, presença de ectoparasitas, contactantes e tratamentos anteriores (Rodrigues, 2016).

O tratamento da doença consiste em eliminar a causa primária, podendo ser feito com medicamentos como glicocorticoides, imunossupressores, antibioticoterapia (Buckley \& Nuttall, 2012) ou por procedimento cirúrgico.

Este trabalho possui como objetivo relatar o caso de um felino diagnosticado com complexo granuloma eosinofilico, desde o diagnóstico ao tratamento da doença, demonstrando a importância da afecção para a medicina veterinária.

\section{Relato de caso}

Foi atendido no hospital veterinário Dr. Vicentte Borelli um felino, macho, SRD, com cerca de cinco meses e $2,5 \mathrm{~kg}$ de peso. Cuja queixa da tutora era, dispnéia inspiratória e espirros por cerca de um mês. Clinicamente, o paciente apresentava edemaciação na mucosa oral com presença de nódulos amarronzados no lábio inferior e lesões ulcerativas nos coxins plantares e palmares. As mucosas estavam normocoradas, hidratação normal e os linfonodos não estavam reativos. Vale salientar que o animal havia sido resgatado e vivia em um abrigo para felinos, além disso, o mesmo vinha sendo tratado pela tutora com amoxicilina associada ao clavulanato de potássio $250 \mathrm{mg}, 1 \mathrm{~mL}$ a cada 12 horas, contudo, sem melhora do quadro.

O lábio inferior encontrava-se edemaciado, mas sem ulceração, havia presença de pequenos nódulos amarronzados, com aspecto escamoso no lábio inferior, os coxins palmares e plantares também apresentavam lesões ulcerativas e despigmentação, contudo, o animal não apresentava sinais de dor ao toque da região.

Suspeitando de calicivirose, granuloma eosinofilico e leucemia felina (FeLV), foram solicitados os exames: hemograma completo, perfil renal (ureia, creatinina, fósforo, cálcio ionizado, sódio e potássio), perfil hepático (ALT, AST, fosfatase alcalina, GGT e bilirrubinas), citologia de tecido sólido dos nódulos no lábio inferior e realizou-se o Senspert FeLV Ag/FIV $\mathrm{Ab}$.

Não houveram alterações consideráveis no hemograma e no bioquímico. Contudo, o resultado da citologia demostrou que a amostra obtida da lesão em lábio inferior, apresentou uma moderada celularidade representada por eosinófilos íntegros e degenerados, as células encontravam-se fragmentadas com núcleos nus e grânulos eosinofílicos citoplasmáticos soltos, compatíveis com o granuloma eosinofílico. Além disso, através do histórico e sinais clínicos do paciente, o mesmo também foi diagnosticado com calicivirose felina.

O tratamento foi instituído após o diagnóstico citopatológico, utilizando predinisolona em gotas, via oral, seguindo o protocolo de seis gotas do dia $1^{\circ}$ ao dia $7^{\circ}$, a cada 12 horas, seis 
gotas do dia $8^{\circ}$ ao $15^{\circ}$ dia, a cada 24 horas e seis gotas do dia $16^{\circ}$ ao dia $24^{\circ}$ a cada 48 horas Utilizou-se também o Parafelis ${ }^{\circledR}$, via oral, para controlar infestações por pulgas, fungos, vermes e outros parasitas, uma borrifada uma vez ao dia, diretamente na boca, na água ou na alimentação e recomendou-se que o deixasse longe de aparelhos eletrônicos e de potes de metal e que fosse realizado o controle de ectoparasitas também no ambiente e nos contactantes. Quanto ao tratamento da calicivirose, foi realizado de forma sintomática.

Após o retorno de 30 dias, observou-se que os sinais clínicos respiratórios do paciente haviam melhorado e as lesões estavam regredindo. Foi observada a redução dos pequenos nódulos orais e da edemaciação oral, bem como as lesões ulcerativas nos coxins, não sendo relatada, até o momento presente, recidiva das lesões.

\section{Discussão}

Estudos sugerem que o Complexo Granuloma Eosinofílico é mais notado em gatos adultos e nas fêmeas, enquanto outros afirmam que acomete principalmente felinos jovens, com menos de dois anos de idade (Larsson \& Lucas, 2016), como foi o caso do paciente deste estudo, todavia, há de se salientar que se tratava de macho de cerca de cinco meses de idade, nesse sentido inferimos que a predileção sexual pode não ser um fator determinante no perfil do paciente.

O diagnóstico do CGE foi estabelecido pelo histórico do animal, dos sinais clínicos, exame citológico, descartando doenças que cursavam com os sinais apresentados pelo animal, como a calicivirose, FIV e FeLV, condizendo com o método de diagnóstico descrito por Brito, (2017) e Buckley \& Nuttall (2012). Não obstante, Hopke \& Sargent (2019) relatam que o diagnóstico é definido através de citologia das lesões e do histopatológico, porém, se deve investigar e descartar todos os possíveis diagnósticos diferenciais que foram utilizados para diagnosticar a causa primária das lesões (Godoy et al., 2020).

A suspeita de calicivirose felina se deu pelo histórico e sinais clínicos apresentados pelo paciente, pois o mesmo vivia em um abrigo para animais e apresentava sinais de infecção de trato respiratório superior. Segundo Hoffmann (2016), o FCV é um dos agentes patogênicos mais comuns em gatos, presente principalmente em ambientes populosos como abrigos e gatis, capaz de provocar quadros variáveis da doença, desde uma infecção assintomática do trato respiratório superior, podendo ser de leve a muito grave, ulcerações na cavidade oral, claudicação e pneumonia.

O paciente apresentava dispneia inspiratória e espirros há cerca de um mês e havia sido tratado anteriormente pela tutora com amoxicilina associada ao clavulanato de potássio. Contudo, o animal não respondeu ao antibiótico, o que pode ser explicado pelo fato de que a causa dos sinais respiratórios se dava por conta de uma doença viral e não bacteriana. $\mathrm{O}$ diagnóstico da calicivirose se deu pelo histórico e sinais clínicos apresentados pelo paciente, como sugerido por Palmero (2014), que afirma que o diagnóstico da calicivirose é bastante desafiador e que o mesmo deve ser baseado nos sinais clínicos, na sua contagiosidade e na alta mortalidade.

No relato em questão, o paciente apresentava somente duas das lesões descritas pela literatura (Buckley \& Nuttall, 2012), que foram o granuloma eosinofílico na região oral e as úlceras indolentes nos coxins palmares e plantares, estas por sua vez, são lesões incomuns (Larsson \& Lucas, 2016). Vale salientar que o paciente não apresentava sinais de dor ao toque das lesões nos coxins, o que condiz com o descrito por Rodrigues (2016). Desse modo entendemos que se faz necessário a avaliação das patas todas as vezes que as lesões mais comuns forem encontradas. 
Por não haver indícios de outras possíveis causas de hipersensibilidade no histórico do paciente e por ser inviável para a tutora de realizar testes de eliminação, por se tratar de um animal de abrigo, e por ser observada a presença de ectoparasitas (pulgas), suspeitou-se que esta fosse a possível causa primária da hipersensibilidade, por isto, administrou-se o Parafelis, para realizar o controle dos ectoparasitas, a fim de confirmar e tratar a causa primária das lesões. Acredita-se que a hipersensibilidade a picada de pulga é a causa primária mais comum de CGE (Lerner, 2018), sendo associada à proteína presente na saliva das pulgas (Hnilica \& Medleau, 2012).

Apesar dos anti-histamínicos serem bastante utilizados em casos de hipersensibilidade a picada de pulgas e em casos idiopáticos (Rodrigues, 2016), não se utilizou para o tratamento deste paciente, pois o tratamento estabelecido com o glicocorticoide, com o controle dos ectoparasitas através do Parafelis e do controle ambiental, foram bastante efetivos. Quanto ao tratamento da calicivirose foi realizado de forma sintomática, como relatado por Hoffmann (2016) que diz que o tratamento deve ser feito através da terapia intensiva de suporte com fluidoterapia, antibióticos, corticosteroides e antivirais.

A maioria dos autores concordam que o tratamento oral para o complexo granuloma eosinofilico com prednisolona deve ser a primeira escolha entre os glicocorticóides (Buckley \& Nuttall, 2012; Hnilica \& Medleau, 2012). No presente relato, o paciente respondeu muito bem ao tratamento com o referido princípio ativo. $\mathrm{O}$ anti-inflamatório atua inibindo todas as fases da resposta inflamatória, reduzindo o acúmulo de leucócitos, linfócitos e eosinófilos, através da liberação de fatores quimiotáticos elaborados no local do processo inflamatório.

\section{Referências}

Brito, A. L. L. (2017). Complexo granuloma eosinofílico em cães e gatos. Universidade Federal da Paraíba.

Buckley, L., \& Nuttall, T. (2012). Feline eosinophilic granuloma complex (ities) some clinical clarification. Journal of Feline Medicine and Surgery, 14(7), 471-481. https://doi.org/10.1177/1098612X12451549.

Godoy, M. L., Nowasky, B., Bresola, S. I. G., \& Pasquali, A. K. S. (2020). Complexo granuloma eosinofílico felino: relato de caso. Seminário de Iniciação Científica e Seminário Integrado de Ensino, Pesquisa e Extensão, 1, e25330-e25330.

Hnilica, K. A., \& Medleau, L. (2012). Dermatologia de pequenos animais: atlas colorido e guia terapêutico. Roca.

Hoffmann, M. L. (2016). Calicivirose sistêmica em gatos.

Hopke, K. P., \& Sargent, S. J. (2019). Novel presentation of eosinophilic granuloma complex in a cat. Journal of Feline Medicine and Surgery Open Reports, 5(2), 2055116919891548. https://doi.org/10.1177/2055116919891548.

Larsson, C. E., \& Lucas, R. (2016). Tratado de medicina externa: dermatologia veterinária. Interbook.

Lerner, D. D. (2018). Complexo granuloma eosinofílico em felinos domésticos. Malaysian Journal of Microbiology, 14(1), 25-33.

Palmero, M. L. (2014). Calicivirus Virulento Sistémico (VS-FCV) (pp. 1-5).

Rodrigues, A. (2016). Complexo granuloma eosinofílico felino. Universidade Federal do Rio Grande do Sul.

Histórico do artigo:

Recebido: 30 de janeiro de 2021

Aprovado: 16 de março de 2021
Licenciamento: Este artigo é publicado na modalidade Acesso Aberto sob a licença Creative Commons Atribuição 4.0 (CC-BY 4.0), a qual permite uso irrestrito, distribuição, reprodução em qualquer meio, desde que o autor e a fonte sejam devidamente creditados. 